\title{
Sequential Offline-Online-Offline (SO3) Measurement Approach for High Frequency LCLC Resonant Converters in the TWTA Applications
}

Zhao, Bin; Zhang, Xin; Zhang, Zhe

Published in:

IEEE Transactions on Industrial Electronics

Link to article, DOI:

10.1109/TIE.2019.2898601

Publication date:

2020

Document Version

Peer reviewed version

Link back to DTU Orbit

Citation (APA):
Zhao, B., Zhang, X., \& Zhang, Z. (2020). Sequential Offline-Online-Offline $\left(\mathrm{SO}^{3}\right.$ ) Measurement Approach for High Frequency LCLC Resonant Converters in the TWTA Applications. IEEE Transactions on Industrial Electronics, 67(2), 1568-1579. https://doi.org/10.1109/TIE.2019.2898601

\section{General rights}

Copyright and moral rights for the publications made accessible in the public portal are retained by the authors and/or other copyright owners and it is a condition of accessing publications that users recognise and abide by the legal requirements associated with these rights.

- Users may download and print one copy of any publication from the public portal for the purpose of private study or research.

- You may not further distribute the material or use it for any profit-making activity or commercial gain

- You may freely distribute the URL identifying the publication in the public portal 


\title{
Sequential Offline-Online-Offline $\left(\mathrm{SO}^{3}\right)$ Measurement Approach for High Frequency LCLC Resonant Converters in the TWTA Applications
}

\author{
Bin Zhao, Member, Xin Zhang, Member, and Zhe Zhang, Senior Member
}

\begin{abstract}
The high frequency $L C L C$ resonant converter is one of the important parts of the two-stage power supply in the space travelling-wave tube amplifier (TWTA) application. Usually, the high frequency LCLC resonant converter utilizes open-loop control and simultaneously sets its switching frequency and duty cycle to the required values to guarantee low cost and high power efficiency. However, the required switching frequency and duty cycle are determined by the transformer parasitic parameters. Therefore, how to measure the real transformer parasitic parameters under the real working conditions precisely becomes very important to the high frequency LCLC resonant converter. The conventional way to measure the transformer parasitics is to employ an offline impedance analyzer. However, the transformer parasitics under real operating conditions may deviate from the offline measured results. The online measurement methods can obtain the real values when the high frequency LCLC resonant converter is working, but these online approaches also mean additional cost and complex implementation requirement. To solve the above problems, a sequential offline-online-offline $\left(\mathrm{SO}^{3}\right)$ measurement method is proposed in this paper. With this $\mathrm{SO}^{3}$ measurement approach, all the real transformer parasitics can be easily obtained in a low cost and simple implementation way, which combines the advantages of both traditional offline and online measurement methods while removing their corresponding shortcomings. The proposed method is validated by the experiments.
\end{abstract}

Index Terms-LCLC resonant converter, measurement method, sequential offline-online-offline $\left(\mathrm{SO}^{3}\right)$, transformer parasitic parameters, travelling-wave tube amplifier.

Manuscript received August 30, 2018; revised November, 6, 2018 accepted January, 23, 2019. This work is fully supported by Singapore ACRF Tier 1 Grant: RG 85/18 and the NTU Start-up Grant for Prof Zhang Xin. (Corresponding author: Xin Zhang).

Bin Zhao is with Space Travelling-wave Tube Research \& Development Center, Institute of Electronics, Chinese Academy of Sciences and is with University of Chinese Academy of Sciences, Beijing, China. He was also with Nanyang Technological University, Singapore. (e-mail: binzhao.iecas@foxmail.com).

Xin Zhang is with Electrical and Electronic Engineering, Nanyang Technological University, Singapore (Corresponding author: e-mail: jackzhang@ntu.edu.sg).

Zhe Zhang is with the Department of Electrical Engineering, Technical University of Denmark (DTU), Denmark.

\section{INTRODUCTION}

A s shown in Fig. 1(a), the two-stage power converter structure is always employed in the power supply of the space travelling-wave tube amplifier (TWTA) [1] - [3]. The first stage is a pre-regulator, where a Buck or Boost converter is utilized, and the second stage is a high frequency $L C L C$ resonant converter (see Fig. 1(b)). The output voltage of the power supply for a space TWTA is regulated by the first stage while the second stage is unregulated with fixed frequency and fixed duty cycle, as a DC transformer [1], [4]. Therefore, the unregulated second stage is required to boost the input voltage, provide the galvanic isolation while keeping high efficiency [5], which poses great challenges on the high frequency $L C L C$ resonant converter.

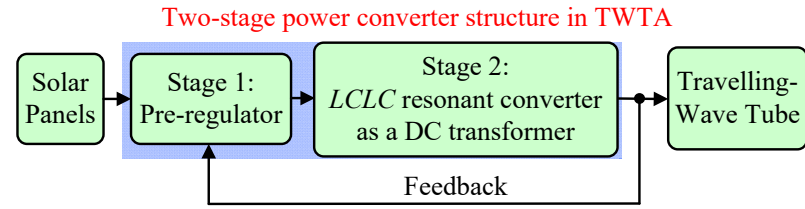

(a)

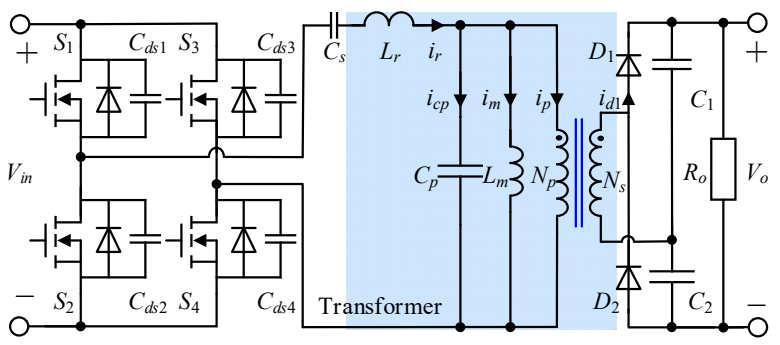

(b)

Fig. 1 Typical power supply in a TWTA: a) Two-stage power converter structure; b) $L C L C$ resonant converter.

As shown in Fig. 1(b), all the transformer parasitics (leakage inductance, $L_{r} ;$ magnetizing inductance, $L_{m} ;$ and parasitic capacitance, $C_{p}$ ) in the high frequency $L C L C$ resonant converter are utilized as the resonant components. In addition, all the transformer parasitics coordinately work together with an extra series capacitor $C_{S}[6]$ to build the $L C L C$ resoant tank. To achieve high efficiency by reducing the switching loss, the high frequency $L C L C$ resonant converter is scheduled to operate under 
zero-voltage-switching (ZVS) and zero-current-switching (ZCS). However, in practice, ZVS and ZCS are very sensitive to the switching frequency and duty cycle, which are largely dependent on the transformer parasitic parameters [5]. Therefore, it is vital to precisely measure the transformer parasitic parameters in the $L C L C$ resonant converter.

The existing transformer parasitics measurement methods can be divided into hybrid offline/online measurement [7], [8], offline measurement [9] - [13] and online measurement [14] - [18]:

The hybrid offline/online measurement methods refer to measure some parameters by the online method while the others are measured by the offline method [7], [8]. This method can be treated as the trade-offs between the traditional online and offline measurement methods. However, as the offline method is applied, this method cannot track all the online parameter variations in the real working conditions.

The offline measurement methods, which are based on the offline impedance analyzer, is widely employed due to their simplicity and low cost [9] - [13]. However, these offline methods do not consider the real online operating conditions of the converter, such as the operating power, the ambient temperature and the core loss, which will degrade the measurement accuracy [19], [20]. Therefore, the calculated frequency and duty cycle cannot guarantee ZVS and ZCS, which will increase the switching loss. However, the switching loss is actually a very crucial issue in high frequency applications, due to the fact that the switching loss is directly proportional to the switching frequency. As a result, when the traditional off-line measurements are utilized, in order to achieve ZVS and ZCS, the "trial and error" method is usually applied to adjust the switching frequency and duty cycle. However, as ZVS and ZCS are not achieved during the debugging process, the conduction of the body diode, the oscillations of the resonant current and the drain-to-source voltages of the switches will cause overvoltage and excess temperature, which may damage the switches [21], [22].

Based on the real-time data processing, the online measurement methods can measure the parameters under real operating conditions, and hence, they have higher accuracy than the offline measurement methods [14] - [18]. However, it should be noted that the TWTA is a high-voltage application. The facility to inject the perturbation, the sensors to measure the corresponding voltage and current, and the data processing equipment, will increase the cost. Considering the cost, the online measurement methods may not be suitable for the TWTA application.

As for the $L C L C$ resonant converter, its characteristics have been investigated and reported [1], [5], [23] - [25]. The stead state analysis of the $L C L C$ resonant converter is detailed explained in [5], [23], [24]. In [5], the working principles and the equations of the main parameters, such as the resonant current, peak magnetizing inductance, are presented. Besides, in [24], the impact of output leakage inductance is investigated. In [25], the performance of the conventional $L L C$ resonant converter is upgraded by adding an extra capacitor to build the $L C L C$ resonant converter.

As mentioned before, the high frequency $L C L C$ resonant converter in Fig. 1(b) in the space TWTA application, it operates under open-loop condition. The main functions of the $L C L C$ resonant converter are boosting the input voltage, providing the electric isolation while keeping high efficiency. As a result, the high frequency $L C L C$ resonant converter should select special switching frequency and duty cycle according to its real transformer parameters to ensure that it can realize ZVS and ZCS in an effective and low-cost way $[1,2]$. Therefore, the conventional offline, online and hybrid offline/online measurements may be not suitable in the space TWTA application.

In order to solve the above problem, a simple, low-cost, and effective sequential offline-online-offline $\left(\mathrm{SO}^{3}\right)$ measurement method is proposed in this paper, which includes three steps. In the first step, the pre-offline measurement is carried out by an impedance analyzer and the offline switching frequency and duty cycle is calculated based on the offline measurement results. In the second step, with the offline calculated switching frequency and duty cycle, the online test is carried out and the test waveforms of the driving signal, resonant current, the drain-to-source voltage of the main switch and the current of the rectifier diode, are recorded. In the third step, the online switching frequency and duty cycle are calculated based on the recorded waveforms, which will be used to update the $L C L C$ resonant converter.

The rest parts of this paper are organized as: the impacts of the transformer parasitics on the $L C L C$ resonant converter are carefully discussed in Section II. In Section III, the operation principles of the $L C L C$ resonant converter are investigated and the circuit analysis is applied to derive the equations of the main parameters, which will be further utilized in Section IV. In Section IV, the $\mathrm{SO}^{3}$ measurement method is proposed and elaborated in detail. The proposed $\mathrm{SO}^{3}$ method is experimentally validated in Section V. Section VI summarizes this paper.

\section{IMPACTS OF THE TRANSFORMER PARASITICS ON THE HIGH FREQUENCY LCLC RESONANT CONVERTERS}

A. Effects of the transformer parasitics on $f_{s_{-} \text {req }}$ and $D_{\text {req }}$

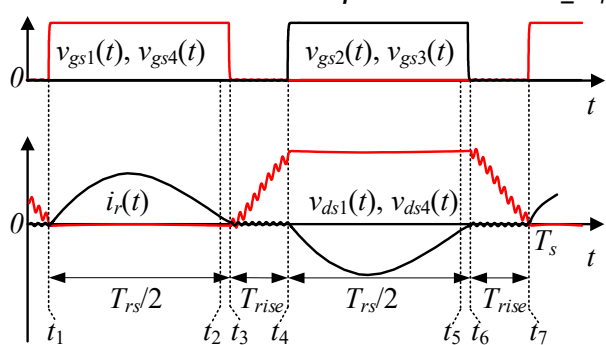

Fig. 2 Typical waveforms of an $L C L C$ resonant converter to calculate $f_{s}$ and $D$

Fig. 2 shows the typical ZVS and ZCS waveforms of the $L C L C$ resonant converter, where the waveforms of interest are the driving signal of $\mathrm{S}_{1}$ and $\mathrm{S}_{4}, v_{g s 1}(t)$ and $v_{g s}(t)$; the drain source voltage of $\mathrm{S}_{1}$ and $\mathrm{S}_{4}, v_{d s 1}(t)$ and $v_{d s}(t)$, and the resonant current, $i_{r}(t) . T_{r s}$ is the resonant period between $L_{r}$ and $C_{s}$.

According to Fig. 2, a complete period (from $t_{1}$ to $t_{7}$ ) consists of a positive half cycle (from $t_{1}$ to $t_{4}$ ) and a negative half cycle (from $t_{4}$ to $t_{7}$ ), where "positive" and "negative" mean the direction of $i_{r}(t)$. In steady state, the positive half cycle is symmetrical with the negative half cycle.

In order to reduce the turn-on loss, it can be seen from Fig. 2 that $\mathrm{S}_{1}$ and $\mathrm{S}_{4}$ are turned on at $t_{1}$, when $v_{d s 1}(t), v_{d s 4}(t)$, and $i_{r}(t)$, 
are zero. In addition, in order to reduce the turn-off loss, it can be seen from Fig. 2 that $\mathrm{S}_{1}$ and $\mathrm{S}_{4}$ are turned off at $t_{3}$, when $v_{d s 1}(t), v_{d s}(t)$, and $i_{r}(t)$, are zero. In this way, the conduction time of $\mathrm{S}_{1}$ and $\mathrm{S}_{4}$ is half of the resonant period, which is $T_{r s} / 2$.

When $\mathrm{S}_{1}$ and $\mathrm{S}_{4}$ are turned off, $v_{d s 1}(t)$ and $v_{d s}(t)$ will increase and be clamped by the input voltage. The increasing time for $v_{d s 1}(t)$ and $v_{d s}(t)$ is $T_{\text {rise }}$.

When $S_{1}$ and $S_{4}$ are clamped, $S_{2}$ and $S_{3}$ will be turned on and

$$
\begin{gathered}
f_{s_{-} \text {req }}=\left(T_{r s}+2 T_{\text {rise }}\right)^{-1}=1 / 2\left\{\pi \sqrt{L_{r} C_{s}}+\sqrt{L_{m} C_{p}} \times\left\{\arccos \left[-\left(\sqrt{1+\left(\pi^{2} L_{r} C_{s}\right) /\left(4 L_{m} C_{p}\right)}\right)^{-1}\right]-\arctan \left(\pi / 2 \sqrt{\left(L_{r} C_{s}\right) /\left(L_{m} C_{p}\right)}\right)\right\}\right\}^{-1} \\
D_{r e q}=T_{r s} /\left(T_{r s}+2 T_{\text {rise }}\right)=\left\{1+1 / \pi \sqrt{\left(L_{m} C_{p}\right) /\left(L_{r} C_{s}\right)} \times\left\{\arccos \left[-\left(\sqrt{1+\left(\pi^{2} L_{r} C_{s}\right) /\left(4 L_{m} C_{p}\right)}\right)^{-1}\right]-\arctan \left(\pi / 2 \sqrt{\left(L_{r} C_{s}\right) /\left(L_{m} C_{p}\right)}\right)\right\}\right\}^{-1}
\end{gathered}
$$

where $T_{\text {rise }}$ is the voltage rising time of the main switch, $\mathrm{S}_{1}$.

It should be noted that the Eq. (1) is to show the relation between the transformer parasitics with $f_{s}$ req and $D_{\text {req }}$ and the further derivation of $T_{\text {rise }}$ will be elaborated in Section III.

By (1(a)) and (1(b)), it can be seen that $f_{s \text { req }}$ and $D_{\text {req }}$ are heavily affected by the transformer parasitics $\left(L_{r}, L_{m}\right.$ and $\left.C_{p}\right)$. In order to figure out this issue, the impacts of $L_{r}, L_{m}, C_{p}$ on $f_{s_{-}}$req and $D_{r e q}$ are depicted in Fig. 3, where all the parameters are in per-unit value. In Fig. 3, the offline measured values of $L_{r}, L_{m}$ and $C_{p}$ are utilized as their base values. Usually, the values of $L_{r}, L_{m}$ and $C_{p}$ under operating conditions may be changed $\pm 20 \%$ around the above base values [19], so the per-unit ranges of $L_{r}$, $L_{m}$ and $C_{p}$ are all set to $[0.8,1.2]$.

Then, by Fig. 3, the impacts of the transformer parasitics on the $f_{s_{-}}$req and $D_{\text {req }}$ are analysed as follows:

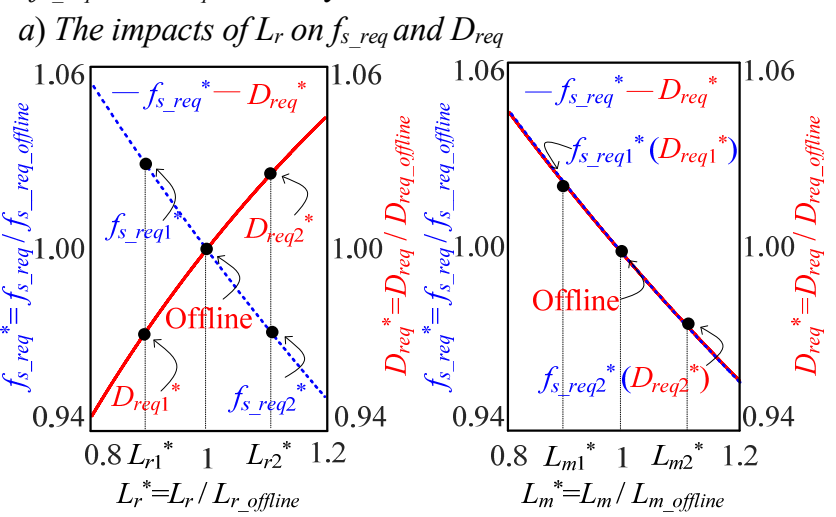

(a)

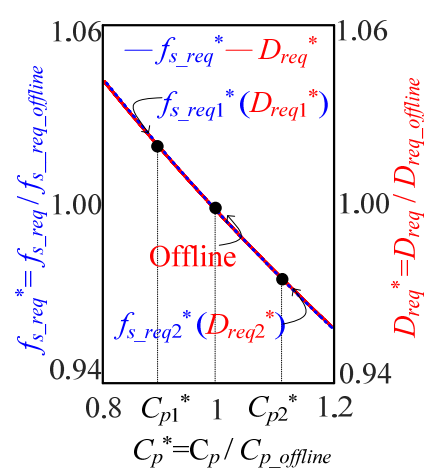

(c)

Fig. 3 Impacts of the transformer parasitics on $f_{s_{-} r e q}$ and $D_{\text {req }}$ : a) $L_{r}$; b) $L_{m}$; c) $C_{p}$

The impacts of $L_{r}$ on $f_{s-r e q}$ and $D_{\text {req }}$ are shown in Fig. 3(a): actually, $L_{r}$ under operating conditions will deviate from the offline measured results. In the first case, $L_{r 1}^{*} \mathrm{~L}_{\mathrm{r} 1}^{*}$ is lower than 1 . It can be seen from Fig. 3(a) that the required frequency, $f_{s_{-} \text {req } 1}^{*}$ is higher than 1 while the required duty cycle, $D^{*}{ }_{\text {req } 1} \mathrm{D}_{\text {req } 1}^{*}$ is lower than 1 . In the second case, $L^{*}{ }_{r 2} \mathrm{~L}_{\mathrm{r} 2}^{*}$ is higher than 1 . It can be seen from Fig. 3(a) that the required frequency, $f_{s_{-} \text {req2 }}^{*} \mathrm{f}_{\mathrm{s}_{\text {req } 2}}^{*}$ is lower than 1 while the required duty cycle, $D_{\text {req } 2}^{*} \mathrm{D}_{\text {req } 1}^{*} \mathrm{D}_{\text {req } 2}^{*}$ is higher than 1 .

b) The impacts of $L_{m}$ on $f_{s \text { req }}$ and $D_{\text {req }}$

The impacts of $L_{m}$ on $f_{s}$ req and $D_{\text {req }}$ are shown in Fig. 3(b): $L_{m}$ under operating conditions will deviate from the offline results. In the first case, $L^{*}{ }_{m 1} \mathrm{~L}_{\mathrm{m} 1}^{*}$ is lower than 1 . It can be seen from Fig. 3(b) both the required frequency, $\mathrm{f}_{\mathrm{s}_{-} \text {req } 1}^{*} f_{s_{-} \text {req1 } 1}^{*}$ and the required duty cycle, $D_{\text {req } 1}^{*} \mathrm{D}_{\text {req } 1}^{*} \mathrm{D}_{\text {req } 1}^{*}$ are higher than 1 . In the second case, $\mathrm{L}_{\mathrm{m} 2}^{*} L^{*}{ }_{m 2}$ is higher than 1 . It can be seen from Fig. 3 (b) that its required frequency, $f_{s_{-} r e q 2}^{*} \mathrm{f}_{\mathrm{s}_{-} \text {req } 2}^{*}$ and required duty cycle $D^{*}{ }_{r e q 2}$ are lower than $1 . \mathrm{L}_{\mathrm{r} 2}^{*}$

c) The impacts of $C_{p}$ on $f_{s_{-}}$req and $D_{\text {req }}$

The impacts of $C_{p}$ on $f_{s_{-} r e q}$ and $D_{\text {req }}$ are shown in Fig. 3(c). $C_{p}$ under operating conditions will deviate from the offline result. In the first case, $C_{p 1}^{*} \mathrm{D}_{\text {req } 1}^{*}$ is lower than 1 . It can be seen from Fig. 3(c) that both the required frequency, $f_{s_{-} \text {req } 1}^{*} \mathrm{f}_{\mathrm{s}_{-} \text {req } 1}^{*}$ and the required duty cycle, $\mathrm{D}_{\text {req } 1}^{*} D^{*}{ }_{\text {req } 1} \mathrm{D}_{\text {req } 1}^{*}$ are higher than 1 . In the second case, $C_{p 2}^{*} \mathrm{~L}_{\mathrm{m} 2}^{*}$ is higher than 1 . It can be seen from Fig. $3(\mathrm{c})$ that the required frequency, $f_{S_{-}}^{*}$ req2 and the required duty cycle, $D^{*}$ req 2 are lower than 1 .

Based on the above analysis, it can be concluded that $f_{s}$ req and $D_{\text {req }}$ are very sensitive to the transformer parasitics. In practice, both $f_{s}$ and $D$ of the $L C L C$ resonant converter are fixed values, which are calculated based on the offline measured transformer parasitics. However, the transformer parasitics under operating conditions will deviate from the offline measured ones, which will further lead to the deviations of the online $f_{s_{-} r e q}$ and $D_{\text {req }}$ from the offline calculated $f_{\text {s req }}$ and $D_{\text {req }}$. Therefore, the deviations of $f_{s_{-} r e q}$ and $D_{\text {req }}$ will lead to the variations of the switching conditions, which means that ZCS and ZVS may not be achived. Therefore, it is necessary to further discuss the effects of $f_{s}$ and $D$ on the switching conditions.

\section{B. Effects of $f_{s}$ and $D$ on the switching conditions}

Possible cases between the real $f_{s}$ or $D$ and the required $f_{s}$ req or $D_{\text {req }}$ are considered: a) $f_{s}>f_{s_{-} r e q}$ or $D>D_{\text {req }}$; b) $f_{s}=f_{s_{-} \text {req }}$ or $D=$ $D_{\text {req }}$; c) $f_{s}<f_{s_{r} \text { req }}$ or $D<D_{\text {req. }}$. Different cases will lead to different switching conditions of the $L C L C$ resonant converter, which can be discussed as follows: 
a) The impacts of $f_{s}$ on the switching conditions: 1) Case 1, $f_{s}$ $>f_{s_{\text {r req }}}$; 2) Case 2, $f_{s_{1}}=f_{s_{-} \text {req }}$; 3) Case $3, f_{s}<f_{s_{-}}$req

In Case 1 (See Fig. 4(a), $f_{s}=110 \% f_{s}$ req is used as an example), as $f_{s}>f_{s_{-}}$req, there is no sufficient time to charge and discharge the output capacitor of $\mathrm{S}_{1}$, which is $C_{d s 1}$ (see Fig. 1(a)). As a result, ZVS of $\mathrm{S}_{1}$ cannot be achieved. In addition, as the time for the resonance between $L_{r}$ and $C_{s}$ is insufficient as well, $\mathrm{ZCS}$ of $\mathrm{S}_{1}$ cannot be achieved as well. Due to the failure to achieve ZVS and ZCS, the switching loss (both turn-on loss and turn-off loss) will increase [26], [27].

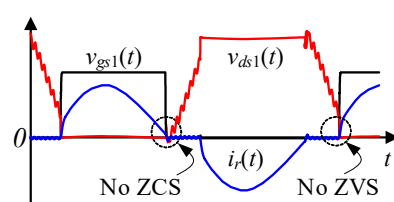

(a)

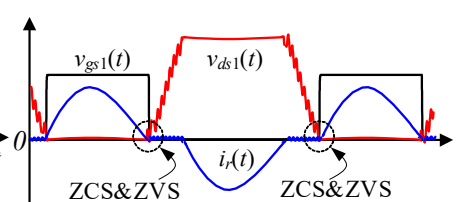

(b)

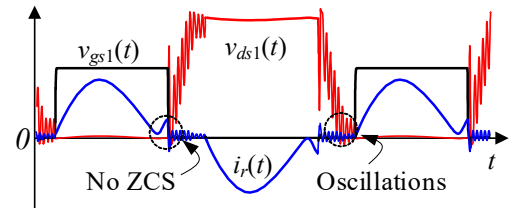

(c)
Fig. 4 Impacts of different $f_{s}$ on the switching conditions of the $L C L C$ resonant converter: a) $f_{s}>f_{s_{-} r e q}\left(f_{s}=110 \% f_{s_{-} r e q}\right)$; b) $f_{s_{s}}=f_{s_{-} r e q}$; c) $f_{s}<f_{s_{-} r e q}\left(f_{s}=90 \% f_{s_{-}} r e q\right)$

In Case 2 (See Fig. 4(b)), with the required $f_{s}$, both ZCS and ZVS of $\mathrm{S}_{1}$ can be achieved very well. Therefore, the switching loss is greatly reduced. In addition, the oscillations are also reduced.

In Case 3 (See Fig. 4(c), $f_{s}=90 \% f_{s_{-}}$req is used as an example), since $f_{s}$ is lower than $f_{s}$ req, the time to charge and discharge $C_{d s 1}$ is more than required. Hence, as shown in Fig. $4(\mathrm{c})$, before $\mathrm{S}_{1}$ is turned on, the voltage oscillation $\left(v_{d s 1}(t)\right)$ occurs among the output capacitors $\left(C_{d s 1}, C_{d s 2}, C_{d s 3}, C_{d s 4}\right), L_{r}$, $L_{m}, C_{p}$ and $C_{s}$. Besides, before $\mathrm{S}_{1}$ is turned off, the current oscillation $\left(i_{r}(t)\right)$ among $L_{r}, L_{m}, C_{p}$ and $C_{s}$ takes place. It is worthy pointing out that the oscillations shown in Fig. 4(c) will increase the conduction loss. In addition, ZCS cannot be achieved, which will increase the switching loss (turn-off loss). As a result, it can be concluded that when $f_{s}$ is lower than $f_{s_{-}}$req, both switching loss and conduction loss will increase.

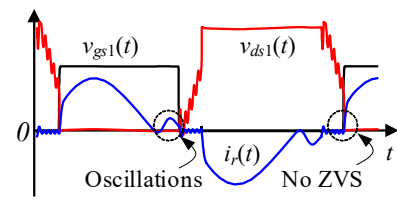

(a)

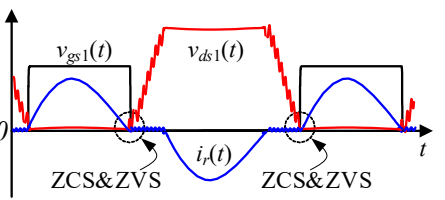

(b)

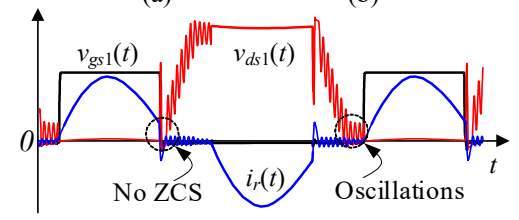

(c)
Fig. 5 Impacts of different $D$ on switching conditions of the $L C L C$ resonant converter: a) $\left.\left.D>D_{\text {req }}\left(D=110 \% D_{\text {req }}\right) ; b\right) D=D_{\text {req }} ; c\right) D<D_{\text {req }}\left(D=90 \% D_{\text {req }}\right)$;

b) The impacts of $D$ on the switching conditions: 1) Case 1, $D>D_{\text {req }}$;) Case 2, $D=D_{\text {req }}$;) Case 3, $D<D_{\text {req }}$

In Case 1 (Fig. 5(a), $D=110 \% D_{\text {req }}$ is used as an example), the time for the resonance between $L_{r}$ and $C_{s}$ is more than required, the current oscillation $\left(i_{r}(t)\right)$ among $L_{r}, L_{m}, C_{p}$ and $C_{s}$ will happen. However, there is no sufficient time to charge and discharge the output capacitor of $S_{1}$. Hence, ZVS of $S_{1}$ cannot be achieved, which will lead to the increase of the switching loss (turn-on loss). In addition, due to the current oscillations, the conduction loss of the $L C L C$ resonant converter will increase.

In Case 2 (See Fig. 5(b)), with the required $D$, both ZCS and ZVS can be achieved. As a result, the switching loss is reduced. In addition, the oscillations are also reduced.

In Case 3 (See Fig. 5(c), $D=90 \% D_{\text {req }}$ is used as an example), since $D$ is smaller than $D_{\text {req }}$, the time to charge and discharge the output capacitor of $S_{1}$ is more than required while the time for the resonance between $L_{r}$ and $C_{s}$ is not sufficient. Hence, by Fig. 5(c), voltage oscillations of $v_{d s 1}(t)$ will take place among the output capacitor of the main switches $\left(C_{d s 1}\right.$, $\left.C_{d s 2}, C_{d s 3}, C_{d s 4}\right), L_{r}, L_{m}, C_{p}$ and $C_{s}$. As ZCS cannot be achieved in Case 3 , the tun-off loss will increase. In addition, the oscillations in Fig. 5(c) will increase the conduction loss.

According to the above analysis, the switching conditions of the $L C L C$ resonant converter are really heavily dependent on $f_{s}$ and $D$, which are closely related with the transformer parasitic parameters. Usually, in the normal case, the transformer parasitics are measured offline. However, the values of the transformer parasitics at idle state are different from those at working state [18]. Therefore, when the calculated $f_{s}$ and $D$ by the offline measured results are utilized in the $L C L C$ resonant converter directly, it may deviate from its actual required values in the real working conditions, which will lead to the failure of ZVS and ZCS, and the unwanted oscillations. This is the problem this paper trying to solve. TABLE I. PARAMETERS FOR SIMULATIONS

\begin{tabular}{cccccc}
\hline \hline Parameter & Value & Parameter & Value & Parameter & Value \\
\hline$L_{r}$ & $0.1 \mu \mathrm{H}$ & $C_{p}$ & $16.0 n \mathrm{~F}$ & $R_{o}$ & $80 \mathrm{k} \Omega$ \\
\hline$L_{m}$ & $8.0 \mu \mathrm{H}$ & $V_{i n}$ & $40 \mathrm{~V}$ & $V_{o}$ & $4800 \mathrm{~V}$ \\
\hline$C_{s}$ & $1.4 \mu \mathrm{F}$ & & & & \\
\hline \hline
\end{tabular}

To illustrate the above problem more intuitively, simulations are carried out to compare the waveforms between accurate and inaccurate $f_{s}$ and $D$. The parameters for the simulations are shown in Table I.

With the parameters in Table I, the simulation waveforms with accurate and inaccurate $f_{s}$ and $D$ are shown in Fig. 6(a) and Fig. 6(b), respectively. By Fig. 6(a), with accurate $f_{s}$ and $D$, both ZCS and ZVS are well achieved in the converter. However, the inaccurate $f_{s}$ and $D$ will lead to failure to achieve ZVS as shown in Fig. 6(b). Therefore, in order to calculate the $f_{s_{-} r e q}$ and $D_{\text {req }}$ under real working conditions precisely, the accurate measurement of the transformer parasitics with fully consideration of the real working conditions is an important issue.

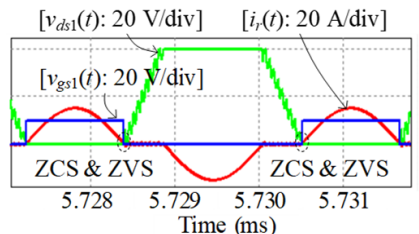

(a)

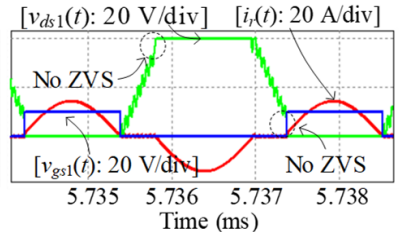

(b)
Fig. 6 Simulation results: a) accurate $f_{s_{-} r e q}(305 \mathrm{kHz})$ and $D_{\text {req }}(35.5 \%)$; b) inaccurate $f_{s_{-} r e q}(320 \mathrm{kHz})$ and $D_{\text {req }}\left(36.5^{\circ}\right)$. 


\section{Operation Principles of the lClC Resonant CONVERTERS FOR THE TWTA APPLICATIONS}

In this section, the operation principles of the $L C L C$ resonant converter are analyzed. In addition, the parameters in each mode are calculated based on the circuit analysis. The equations derived in this section will be used in the proposed $\mathrm{SO}^{3}$ measurement method in section IV.

Before the analysis of the operation principles, the following assumptions are made:

- The input and output voltage are constant;

- All the components are ideal, which means there is no power losses in the converter.

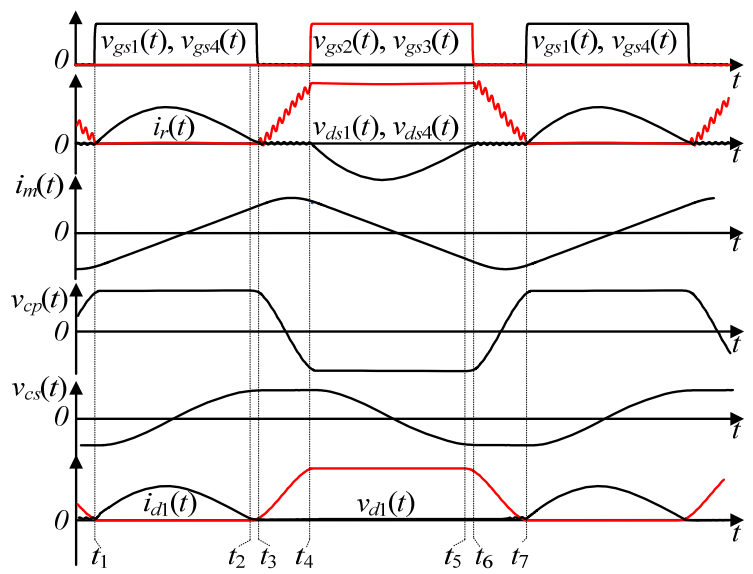

Fig. 7 Typical ZCS and ZVS waveforms of an $L C L C$ resonant converter

The waveforms of interest are: the driving signals of $\mathrm{S}_{1}, \mathrm{~S}_{2}$, $\mathrm{S}_{3}$ and $\mathrm{S}_{4}, v_{g s 1}(t), v_{g s 2}(t), v_{g s 3}(t)$ and $v_{g s 4}(t)$; the resonant current, $i_{r}(t)$; the magnetizing current, $i_{m}(t)$; the voltage across the series capacitor $\left(C_{s}\right), v_{c s}(t)$; the voltage across the parallel capacitor $\left(C_{p}\right), v_{c p}(t)$; the voltage across the parasitic capacitor of $\mathrm{S}_{1}$, $v_{d s 1}(t)$ (same as $\left.v_{d s}(t)\right)$; the voltage across the rectifier diode $\mathrm{D}_{1}$, $v_{d 1}(t)$; and the current through the rectifier diode $\mathrm{D}_{1}, i_{d 1}(t)$. The typical ZCS and ZVS waveforms of an $L C L C$ resonant converter are shown in Fig. 7.

The operation principles of the $L C L C$ resonant converter can be divided into six modes and each mode will be elaborated as follows:

\section{A. Operation principles of Mode 1 ([t $\left.t_{1}, t_{2}\right]$ in Fig. 7$)$}

The waveforms in Mode 1 are shown in Fig. 7 while the equivalent circuit of Mode 1 is shown in Fig. 8(a).

Prior to Mode $1, i_{r}(t)$ is 0 and $v_{d s 1}(t)$ and $v_{d s}(t)$ are also 0 . As a result, at $t_{1}, \mathrm{~S}_{1}$ and $\mathrm{S}_{4}$ are turned on, both ZCS and ZVS of $\mathrm{S}_{1}$ and $\mathrm{S}_{4}$ are achieved. In addition, the voltage of $C_{p}$ has increased to $\left(N_{p} V_{o}\right) /\left(2 N_{s}\right)$ and will be clamped because the diode $\mathrm{D}_{1}$ is conducting.

Similarly, at $t_{1}$, the voltage across the diode $\mathrm{D}_{1}$ is 0 and the current through the diode $\mathrm{D}_{1}$ is also 0 . Therefore, the rectifier diode $\mathrm{D}_{1}$ also operates in ZCS and ZVS.

Therefore, the resonance will begin between $L_{r}$ and $C_{s} . i_{r}(t)$ can be calculated by

$$
i_{r}(t)=I_{r p} \sin \left[2 \pi f_{r s}\left(t-t_{1}\right)\right]
$$

where $I_{r p}$ is the peak value of the resonant current.

As $C_{p}$ is clamped, $i_{m}(t)$ will increase linearly, which is

$$
i_{m}(t)=\left.i_{m}(t)\right|_{t=t_{1}}+\left(N_{p} V_{o}\right) /\left(2 N_{s} L_{m}\right)\left(t-t_{1}\right)
$$

The voltage of $C_{s}$ can be calculated by

$$
v_{c s}(t)=\left.v_{c s}(t)\right|_{t=t_{1}}+1 / C_{s} \int_{t_{1}}^{t} i_{r}(t) d t
$$

In Mode 1 , when $i_{r}(t)$ is equal to $i_{m}(t), \mathrm{D}_{1}$ will turn off naturally. Mode 1 ends.
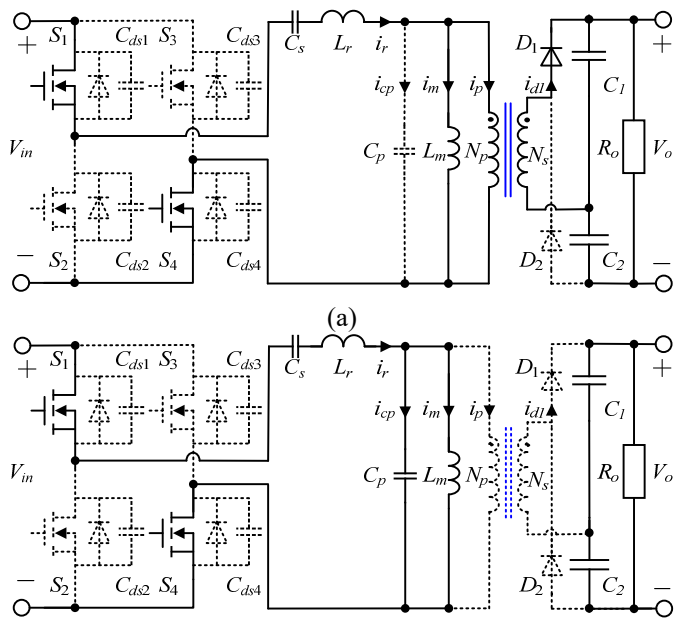

(b)

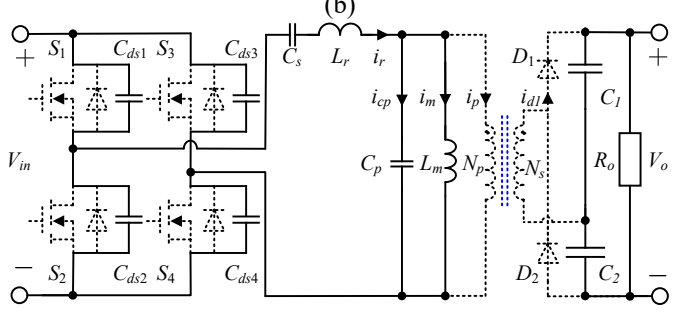

(c)

Fig. 8 Equivalent circuit in each Mode: a) Mode 1; b) Mode 2; c) Mode 3

\section{B. Operation principles of Mode 2 ([ $\left[\mathrm{t}_{2}, t_{3}\right]$ in Fig. 7)}

The waveforms of Mode 2 are shown in Fig. 7 and the equivalent circuit of Mode 2 is shown in Fig. 8(b). In Mode 2, as $\mathrm{D}_{1}$ is off, $C_{p}$ is not clamped any more. The equivalent circuit of Mode 2 in $s$ domain is shown in Fig. 9.

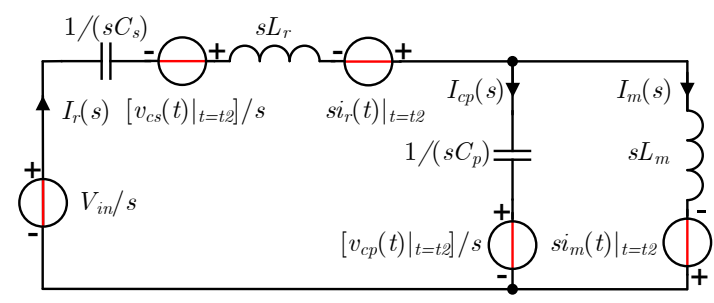

Fig. 9 Equivalent circuit of Mode 2 in $s$ domain

Based on Fig. 9, the following equations can be derived:

$$
\left\{\begin{array}{l}
\left(s L_{r}+\frac{C_{p}+C_{s}}{s C_{s} C_{p}}\right) I_{r}(s)+\left(-\frac{1}{s C_{p}}\right) I_{m}(s)=\frac{V_{i n}+\left.s L_{r} i_{r}(t)\right|_{t=t_{2}}-\left.v_{c s}(t)\right|_{t=t_{2}}-\left.v_{c p}(t)\right|_{t=t_{2}}}{s} \\
\left(-\frac{1}{s C_{p}}\right) I_{r}(s)+\left(s L_{m}+\frac{1}{s C_{p}}\right) I_{m}(s)=\frac{\left.v_{c p}(s)\right|_{t=t_{2}}+\left.s L_{m} i_{m}(s)\right|_{t=t_{2}}}{s}
\end{array}\right.
$$


As a result, $i_{r}(t)$ and $i_{m}(t)$ can be calculated, which are

$$
\begin{gathered}
i_{r}(t)=-\sqrt{\frac{C_{p}}{L_{r}}}\left[\left.\left(1-\frac{L_{r}}{L_{m}}\right) v_{c s}(t)\right|_{t=t_{2}}+\frac{L_{r}}{L_{m}} V_{i n}\right] \sin \left(\frac{t}{\sqrt{L_{r} C_{p}}}\right)+\left.i_{r}(t)\right|_{t=t_{2}} \cos \left(\frac{t}{\sqrt{L_{m} C_{s}}}\right)+\sqrt{\frac{C_{s}}{L_{m}}}\left[V_{i n}+\left.\left(-1+\frac{C_{p}}{C_{s}}\right) v_{c s}(t)\right|_{t=t_{2}}\right] \sin \left(\frac{t}{\sqrt{L_{m} C_{s}}}\right) \\
i_{m}(t)=\left.v_{c s}(t)\right|_{t=t 2} \frac{L_{r}}{L_{m}} \sqrt{\frac{C_{p}}{L_{r}}} \sin \left(\frac{t}{\sqrt{L_{r} C_{p}}}\right)+\left.i_{m}(t)\right|_{t=t 2} \cos \left(\frac{t}{\sqrt{L_{m} C_{s}}}\right)+\sqrt{\frac{C_{s}}{L_{m}}}\left[V_{i n}-\left.v_{c s}(t)\right|_{t=t 2}\right] \sin \left(\frac{t}{\sqrt{L_{m} C_{s}}}\right)
\end{gathered}
$$

The voltage of $C_{p}$ can be calculated by

$$
v_{c p}(t)=\left(N_{p} V_{o}\right) /\left(2 N_{s}\right)+1 / C_{s} \int_{t_{1}}^{t}\left[i_{r}(t)-i_{m}(t)\right] d t
$$

When $i_{r}(t)$ decreases to $0, S_{1}$ and $S_{4}$ will be turned off. Mode 2 ends.

\section{Operation principles of Mode 3 ( $\left[t_{3}, t_{4}\right]$ in Fig. 7$)$}

The waveforms of Mode 3 are shown in Fig. 7 and the equivalent circuit is shown in Fig. 8(c).

In Mode 3, since all the switches are off, a complex resonance begins among $C_{d s 1}, C_{d s 2}, C_{d s 3}, C_{d s 4}, C_{s}, L_{r}, C_{p}$ and $L_{m}$. The equivalent circuit of Mode 3 in $s$ domain is shown in Fig. 10. According to Fig. 10, based on the circuit analysis,

$$
\begin{aligned}
& \text { the following equations can be derived to calculate the } \\
& \left\{\begin{array}{l}
2 I_{1}-I_{2}-I_{3}=0 \\
-\frac{1}{s C} I_{1}+\frac{L_{r} C_{d s} C_{p} C_{s} s^{2}+2\left(C_{d s} C_{p}+C_{p} C_{s}+C_{d s} C_{s}\right)}{s C_{d s} C_{p} C_{s}} I_{2}-\frac{s^{2} L_{r} C_{p} C_{s}+C_{p}+C_{s}}{s C_{p} C_{s}} I_{3}+\frac{1}{s C_{p}} I_{m}=\frac{\left.v_{c p}(t)\right|_{t=t_{3}}+\left.v_{c s}(t)\right|_{t=t_{3}}-V_{i n}-\left.s L_{r} i_{r}(t)\right|_{t=t_{3}}}{s} \\
\frac{1}{s C} I_{1}+\frac{s^{2} L_{r} C_{p} C_{s}+C_{p}+C_{s}}{s C_{p} C_{s}} I_{2}-\frac{L_{r} C_{d s} C_{p} C_{s} s^{2}+2\left(C_{d s} C_{p}+C_{p} C_{s}+C_{d s} C_{s}\right)}{s C_{d s} C_{p} C_{s}} I_{3}+\frac{1}{s C_{p}} I_{m}=\frac{-V_{i n}+\left.v_{c p}(t)\right|_{t=t_{3}}+\left.v_{c s}(t)\right|_{t=t_{3}}-\left.s L_{r} i_{r}(t)\right|_{t=t_{3}}}{s} \\
-\frac{1}{s C_{p}} I_{2}+\frac{1}{s C_{p}} I_{3}-\left(\frac{1}{s C_{p}}+s L_{m}\right) I_{m}=-\left.L_{m} i_{m}(t)\right|_{t=t_{3}}-\frac{\left.v_{c p}(t)\right|_{t=t_{3}}}{s}
\end{array}\right.
\end{aligned}
$$

$i_{1}(t), i_{2}(t)$ and $i_{3}(t)$ can be found from (8), which are

$$
\begin{gathered}
i_{1}(t)=0 \\
i_{2}(t)=-1 / 2\left\{\gamma_{11} \cos \left[\left(t-t_{3}\right) / \sqrt{L_{r} C_{d s}}\right]+\gamma_{12} \sin \left[\left(t-t_{3}\right) / \sqrt{L_{r} C_{d s}}\right]+\gamma_{13} \cos \left[\left(t-t_{3}\right) / \sqrt{L_{m} C_{p}}\right]+\gamma_{14} \sin \left[\left(t-t_{3}\right) / \sqrt{L_{m} C_{p}}\right]\right\} \\
i_{3}(t)=1 / 2\left\{\gamma_{21} \cos \left[\left(t-t_{3}\right) / \sqrt{L_{r} C_{d s}}\right]+\gamma_{22} \sin \left[\left(t-t_{3}\right) / \sqrt{L_{r} C_{d s}}\right]+\gamma_{23} \cos \left[\left(t-t_{3}\right) / \sqrt{L_{m} C_{p}}\right]+\gamma_{24} \sin \left[\left(t-t_{3}\right) / \sqrt{L_{m} C_{p}}\right]\right\} \\
i_{m}(t)=\gamma_{31} \cos \left[\left(t-t_{3}\right) / \sqrt{L_{r} C_{d s}}\right]+\gamma_{32} \sin \left[\left(t-t_{3}\right) / \sqrt{L_{r} C_{d s}}\right]+\gamma_{33} \sin \left[\left(t-t_{3}\right) / \sqrt{L_{m} C_{p}}\right]+\gamma_{34} \cos \left[\left(t-t_{3}\right) / \sqrt{L_{m} C_{p}}\right]
\end{gathered}
$$

where $\gamma_{11}, \gamma_{12}, \gamma_{13}, \gamma_{14}$ can be calculated by

$$
\begin{gathered}
\gamma_{11}=\left.i_{r}(t)\right|_{t=t_{3}}-C_{d s} /\left.C_{p} i_{m}(t)\right|_{t=t_{3}} \\
\gamma_{12}=\sqrt{C_{d s} / L_{r}}\left[V_{i n}-\left.v_{c p}(t)\right|_{t=t_{3}}-\left.v_{c s}(t)\right|_{t=t_{3}}\right] \\
\gamma_{13}=C_{d s} /\left.C_{p} i_{m}(t)\right|_{t=t_{3}} \\
\gamma_{14}=\left[V_{i n}-\left.v_{c s}(t)\right|_{t=t_{3}}\right] C_{d s} \sqrt{1 /\left(C_{p} L_{m}\right)}
\end{gathered}
$$

$\gamma_{21}, \gamma_{22}, \gamma_{23}, \gamma_{4}$ can be calculated by

$$
\begin{gathered}
\gamma_{21}=\left.i_{r}(t)\right|_{t=t_{3}}-C_{d s} /\left.C_{p} i_{m}(t)\right|_{t=t_{3}} \\
\gamma_{22}=\sqrt{C_{d s} / L_{r}}\left[V_{i n}-\left.v_{c p}(t)\right|_{t=t_{3}}-\left.v_{c s}(t)\right|_{t=t_{3}}\right] \\
\gamma_{23}=C_{d s} /\left.C_{p} i_{m}(t)\right|_{t=t_{3}} \\
\gamma_{24}=\left[V_{i n}-\left.v_{c s}(t)\right|_{t=t_{3}}\right] C_{d s} \sqrt{1 /\left(C_{p} L_{m}\right)}
\end{gathered}
$$

$\gamma_{31}, \gamma_{32}, \gamma_{33}, \gamma_{34}$ can be calculated by

$$
\begin{gathered}
\gamma_{31}=-\left(L_{r} C_{d s}\right) /\left.L_{m} C_{p} i_{r}(t)\right|_{t=t_{3}} \\
\gamma_{32}=\left[V_{i n}-\left.v_{c s}(t)\right|_{t=t_{3}}\right]\left(L_{r} C_{d s}\right) /\left(L_{m} C_{p}\right) \sqrt{C_{d s} / L_{r}} \\
\gamma_{33}=\left\{\left.v_{c p}(t)\right|_{t=t_{3}}-C_{d s} / C_{p}\left[V_{i n}-\left.v_{c p}(t)\right|_{t=t_{3}}-\left.v_{c s}(t)\right|_{t=t_{3}}\right]\right\} \sqrt{C_{p} / L_{m}} \\
\gamma_{34}=\left.i_{m}(t)\right|_{t=t_{3}}
\end{gathered}
$$

According to (9), $i_{r}(t), v_{c p}(t), v_{c s}(t), v_{d s 1}(t)$ in Mode 3 can be calculated by

$$
\begin{gathered}
i_{r}(t)=i_{3}(t)-i_{2}(t) \\
v_{c p}(t)=\left.v_{c p}(t)\right|_{t=t_{3}}+1 / C_{p} \int_{t_{3}}^{t}\left[i_{3}(t)-i_{2}(t)-i_{m}(t)\right] d t \\
v_{c s}(t)=\left.v_{c s}(t)\right|_{t=t_{3}}+1 / C_{s} \int_{t_{3}}^{t}\left[i_{3}(t)-i_{2}(t)\right] d t \\
v_{d s 1}(t)=v_{d s 4}(t)=1 / C_{d s} \int_{t_{3}}^{t}\left[-i_{3}(t)\right] d t \\
v_{d s 2}(t)=v_{d s 3}(t)=V_{i n}+1 / C_{d s} \int_{t_{3}}^{t}\left[-i_{3}(t)\right] d t
\end{gathered}
$$

In Mode $3, v_{d s 1}(t)$ and $v_{d s}(t)$ will increase to $V_{\text {in }}$ while $v_{d s 2}(t)$ and $v_{d s 3}(t)$ will decrease to 0 . In addition, $v_{c p}(t)$ will decrease then increase to $-V_{i n}$. When $v_{d s 2}(t)$ and $v_{d s 3}(t)$ decrease to $0, \mathrm{~S}_{2}$ and $\mathrm{S}_{3}$ will be turned on and Mode 3 ends.

Combing (9) and (13), the voltage rising time of $\mathrm{S}_{1}, T_{\text {rise }}$, which has been mentioned Section II, can be calculated by $T_{r i s e}=1 /\left(2 \pi f_{r p}\right)\left\{\arccos \left[-\left(\sqrt{\left(\pi f_{r p}\right) /\left(2 f_{r s}\right)}\right)^{-1}\right]-\arctan \left[\left(\pi f_{r p}\right) /\left(2 f_{r s}\right)\right]\right\}$

where $f_{r p}$ is the resonant frequency between $C_{p}$ and $L_{m}$.

The second half period is symmetrical with the first half period, with Mode 4 similar to Mode 1 from $t_{4}$ to $t_{5}$; Mode 5 similar to Mode 2 from $t_{5} \mathrm{t}_{6}$ to $t_{6} \mathrm{t}_{7}$ and Mode 6 similar to Mode 3 from $t_{6}$ to $t_{7}$. 
In the following section, the parameters derived in this section will be employed for the calculations in the proposed $\mathrm{SO}^{3}$ measurement method.

\section{Proposed Sequential Offline-ONLINE-OfFline $\left(\mathrm{SO}^{3}\right)$ MEASUREMENT METHOD}

In this section, an $\mathrm{SO}^{3}$ measurement method for the $L C L C$ resonant converter is proposed, which not only inherits the low-cost and simple advantages of the traditional offline measurement method, but also enjoys the accuracy of all the transformer parasitics like the online measurement method. In the first part, the calculations of the transformer parasitics based on the waveforms are derived. In the second part, based on the derived equations, an $\mathrm{SO}^{3}$ measurement method is proposed and the procedures are elaborated in details.

\section{A. Preliminary: derivation of the transformer parasitics by the working waveforms}

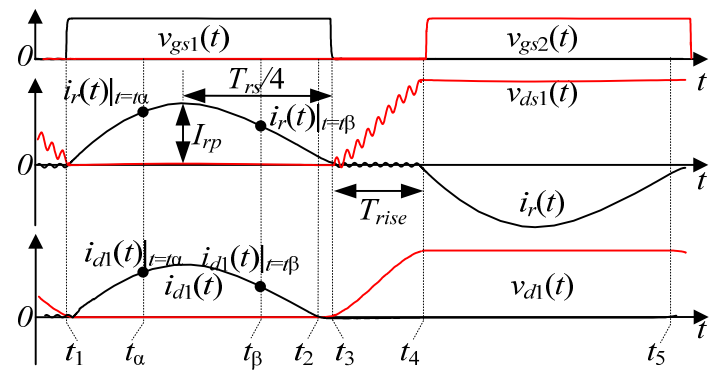

Fig. 11 Typical waveforms of the $L C L C$ converter for parasitics calculations

a) Calculation of the leakage inductance $\left(L_{r}\right)$

As mentioned in the previous section, in Mode 1, the resonance takes place between $L_{r}$ and $C_{s}$. since $C_{s}$ is the external capacitor and its parameter is a known value, $L_{r}$ can be calculated by

$$
L_{r}=1 /\left(4 \pi^{2} f_{r s}^{2} C_{s}\right)
$$

where $T_{r s}$ is the resonant period corresponding to $f_{r s}$. In the proposed $\mathrm{SO}^{3}$ method, $T_{r s}$ is found by a quarter cycle of $T_{r s}$, which is shown in Fig. 11.

b) Calculation of the magnetizing inductance $\left(L_{m}\right)$

Based on (4), the voltage of $C_{s}$ at $t_{2}$ can be calculated by

$$
\left.v_{c s}(t)\right|_{t=t_{2}}=\left.v_{c s}(t)\right|_{t=t_{1}}+\left(1 / \sqrt{L_{r} C_{s}}\right) \cdot \int_{t_{1}}^{t_{2}} \Delta \cdot \sin \left[2 \pi f_{r s}\left(t-t_{1}\right)\right] d t
$$

where $\Delta=V_{i n}-\left.v_{c s}(t)\right|_{t=t 1}-\left(N_{p} V_{o} /\left(2 N_{s}\right)\right) V_{o}, V_{o}$ is the output voltage. $N_{p}$ and $N_{s}$ are the number of the turns in the primary winding and secondary winding, respectively.

In steady state, the waveform of $v_{c s}(t)$ is symmetrical. Therefore, the voltage gain of the $L C L C$ resonant converter can be found as

$$
V_{o} / V_{i n}=2 N_{s} / N_{p}
$$

In Mode $1, C_{p}$ is clamped, there is no current through $C_{p}$. Thus, the magnetizing current, $i_{m}(t)$ can be calculated by

$$
i_{m}(t)=i_{r}(t)-N_{s} / N_{p} \cdot i_{d 1}(t)
$$

where $i_{d 1}(t)$ is the current of $D_{1}$.

As $D_{1}$ is on, $L_{m}$ is clamped by $N_{p} V_{o} / 2 N_{s}$. According to (17), the relation between $L_{m}$ and the voltage of the magnetizing inductance is

$$
V_{L m}=V_{o} \cdot\left[N_{p} /\left(2 N_{s}\right)\right]=V_{i n}=L_{m} \cdot\left[d i_{m}(t) / d t\right]
$$

where $V_{L m}$ is the voltage of the magnetizing inductance.
As $L_{m}$ is clamped, $i_{m}(t)$ increases linearly. As a result, (19) can be replaced by a difference equation by selecting two moments, $t_{\alpha}$ and $t_{\beta}$ from $t_{1}$ and $t_{2}$, which can be seen from Fig. 11. Combing (3), (18) and (19), $L_{m}$ can be calculated by

$$
L_{m}=\frac{V_{i n}\left(t_{\alpha}-t_{\beta}\right)}{\left[\left.i_{r}(t)\right|_{t=t_{\alpha}}-\left.i_{r}(t)\right|_{t=t_{\beta}}\right]-N_{s} / N_{p}\left[\left.i_{d 1}(t)\right|_{t=t_{\alpha}}-\left.i_{d 1}(t)\right|_{t=t_{\beta}}\right]}
$$

where $t_{\alpha}$ and $t_{\beta}$ are two moments from $t_{1}$ to $t_{2} ;\left.i_{r}(t)\right|_{t=t \alpha},\left.i_{r}(t)\right|_{t=t \beta}$ are the resonant currents at $t_{\alpha}$ and $t_{\beta}$ respectively. While $\left.i_{d 1}(t)\right|_{t=t \alpha}$, $\left.i_{d 1}(t)\right|_{t=t \beta}$ are the currents of $D_{1}$ at $t_{\alpha}$ and $t_{\beta}$ restively.

c) Calculation of the parasitic capacitance $\left(C_{p}\right)$

As shown in Fig. 11, from $t_{3}$ to $t_{4}, v_{d s 1}(t)$ will increase from 0

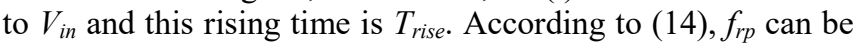
calculated by

$$
f_{r p}=1 /\left(2 \pi T_{r i s e}\right)\left\{\cos ^{-1}\left[-\left(\left(\pi f_{r p}\right) /\left(2 f_{r s}\right)\right)^{-0.5}\right]-\tan ^{-1}\left[\left(\pi f_{r p}\right) /\left(2 f_{r s}\right)\right]\right\}
$$

However, since (21) is an implicit function, the numerical solution of $f_{r p}$ will be found by iterations and the flowchart is given in Fig. 12. With $f_{r p}, C_{p}$ can be calculated by

$$
\begin{aligned}
& C_{p}=1 /\left(4 \pi^{2} f_{r p}^{2} L_{m}\right)
\end{aligned}
$$

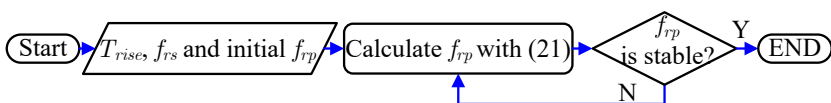

Fig. 12 Iteration flowchart of (21) to calculate $f_{r p}$

Based on (15), (20) and (22), all the transformer parasitics can be calculated based on the waveforms. An $\mathrm{SO}^{3}$ measurement method is proposed, which will be elaborated in the following part.

\section{B. The Proposed $\mathrm{SO}^{3}$ measurement method}

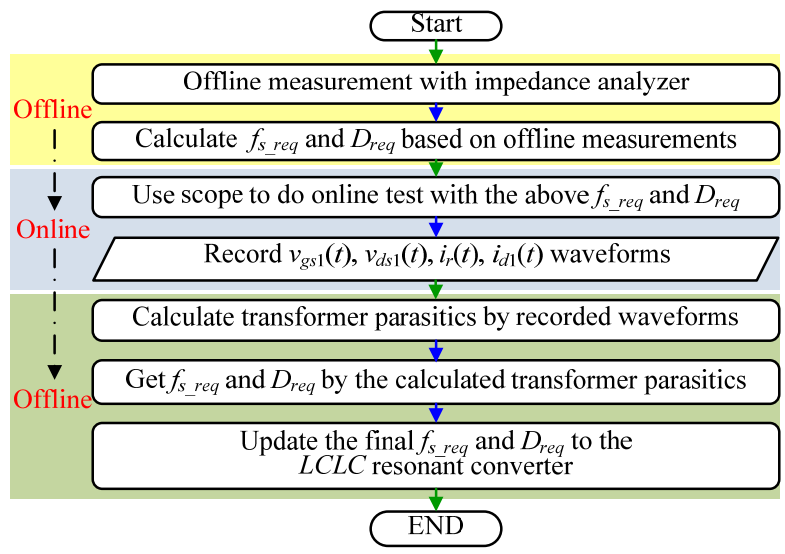

Fig. 13 Flowchart of proposed $\mathrm{SO}^{3}$ measurement method

In this part, an $\mathrm{SO}^{3}$ measurement method is proposed. The flowchart of the $\mathrm{SO}^{3}$ method is depicted in Fig. 13.

As shown in Fig. 13, the $\mathrm{SO}^{3}$ meaurement method includes three steps, which are pre-offline measurement, utilize oscilloscope to do online test and to record the test waveforms and Offline calculations and corrections of the final $f_{s_{-}}$req and $D_{\text {req. }}$.

\section{a) Step 1: Pre-offline measurement}

In the first step, the transformer parasitics are measured by an offline impedance analyzer. The purpose of this step is to obtain the offline measured transformer parasitics and calculate the offline $f_{s-r e q}$ and $D_{\text {req }}$ with (1a) and (1b). With the offline $f_{s \text { req }}$ and $D_{\text {req }}$, the $L C L C$ resonant converter can be initially operated.

b) Step 2: Utilize oscilloscope to do the online test and record the test waveforms 
With the calculated $f_{s \text { req }}$ and $D_{\text {req }}$ in Step 1 , the $L C L C$ resonant converter is configured to operate under real working conditions. Then, the real working waveforms of $v_{g s 1}(t), v_{d s 1}(t)$, $i_{r}(t)$ and $i_{d 1}(t)$ under real working conditions are recorded by the scope.

It is worthy to point out that since the waveforms are recorded under the real working conditions, the deviations of the transformer parasitics caused by the working conditions are captured, which means the proposed $\mathrm{SO}^{3}$ measurement method can enjoy the same accuracy with the online method.

The online recorded waveforms will be used for the calculations of the transformer parasitics in the Step 3.

c) Step 3: Offline calculations and corrections of the final $f_{s_{-} \text {req }}$ and $D_{\text {req }}$

Based on the recorded waveforms in step 2, the real online transformer parasitic parameters can be mathematically calculated and no additional test equipment is needed.

The detailed calculation procedures in Step 3 are shown as follows:

At first, $\boldsymbol{L}_{\boldsymbol{r}}$ is calculated by (15), which is based on $T_{r s} / 4$ measured in the recorded waveforms.

Secondly, two time points, $t_{\alpha}$ and $t_{\beta}$ are selected. The time difference $\left(\Delta t=t_{\beta}-t_{\alpha}\right)$ is calculated. The resonant current at $t_{\alpha}$ and $t_{\beta}$ are measured, which are $\left.i_{r}(t)\right|_{t=t \alpha}$ and $\left.i_{r}(t)\right|_{t=t \beta}$. In addition, the current of $\mathrm{D}_{1}$ at $t_{\alpha}$ and $t_{\beta}$, is also measured, which are $\left.i_{d 1}(t)\right|_{t=t \alpha}$ and $\left.i_{d 1}(t)\right|_{t=t \beta}$. With $\Delta t,\left.i_{r}(t)\right|_{t=t \alpha},\left.i_{r}(t)\right|_{t=t \beta},\left.i_{d 1}(t)\right|_{t=t \alpha}$ and $\left.i_{d 1}(t)\right|_{t=t \beta}, \boldsymbol{L}_{\boldsymbol{m}}$ is calculated by (20).

Thirdly, $T_{\text {rise }}$ is measured in the recorded waveforms. With $T_{r i s e}$ and $f_{r s}, f_{r p}$ is calculated with (21). Then, $\boldsymbol{C}_{\boldsymbol{p}}$ is calculated by (22).

After the transformer parasitics are calculated, $\boldsymbol{f}_{\boldsymbol{s}}$ and $\boldsymbol{D}$ will be eventually calculated by (1(a)) and (1(b)). As the waveforms are recorded online, the calculated $f_{s}$ and $D$ actually enjoy the accuracy as the online measured results, which means the real operating conditions of the $L C L C$ resonant converter are considered.

Finally, the above calculated $f_{s}$ and $D$ will be used to update the $L C L C$ resonant converter.

$\mathrm{Up}$ to this moment, the proposed $\mathrm{SO}^{3}$ measurement method is finished. In the following section, the proposed $\mathrm{SO}^{3}$ measurement method will be validated by the experiments.

\section{EXPERIMENTAL VALIDATION}

In this section, as shown in Fig. 14, a real $L C L C$ resonant converter with a planar transformer, which is utilized in the TWTA application, is tested to validate the proposed $\mathrm{SO}^{3}$ measurement method. The type of the MOSFETs is RJK0656DPB from Renesas Electronics while that of the rectifier diode is GB01SLT12-214 from GeneSiC Semiconductor. To validate the effectiveness of the proposed method, in the first part, the transformer parasitics are measured by the traditional offline measurement method. In the second part, the proposed $\mathrm{SO}^{3}$ measurement method is used for the $L C L C$ resonant converter. In the third part, the offline measurement method and proposed $\mathrm{SO}^{3}$ measurement method is further compared by the efficiency under different input voltages and loads.

\section{A. Experimental results with the offline measurement method}

The parasitics of the planar transformer for the $L C L C$ resonant converter are measured with an offline impedance analyser (E4990A) at $25^{\circ} \mathrm{C}$. The measured results are shown in Table II.

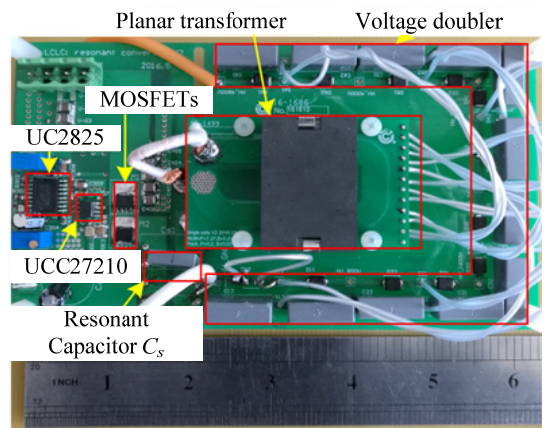

Fig. 14 The $L C L C$ resonant converter with the planar transformer.

\begin{tabular}{cccccc}
\multicolumn{6}{c}{ TABLE II. PARASITICS OF THE TRANSFORMER BY OFFLINE MEASUREMENT $\left(25^{\circ} \mathrm{C}\right)$} \\
\hline \hline Parameter & Value & Parameter & Value & Parameter & Value \\
\hline$L_{r}$ & $0.11 \mu \mathrm{H}$ & $C_{p}$ & $13.8 n \mathrm{~F}$ & $\boldsymbol{D}$ & $\mathbf{7 2 . 3 \%}$ \\
\hline$L_{m}$ & $8.5 \mu \mathrm{H}$ & $\boldsymbol{f}_{s}$ & $\mathbf{3 4 7} \mathbf{k H z}$ & & \\
\hline \hline
\end{tabular}

With the offline measured transformer parasitics, $f_{s}$ and $D$ are calculated with (1a) and (1b), which are $347 \mathrm{kHz}$ and $72.3 \%$, as show in Table II. The LCLC resonant converter is tested with the offline calculated $f_{s}$ and $D$ under the rated input voltage (40 V) and output power $(288 \mathrm{~W})$. In order to investigate the effect of the operating temperature on the proposed measurement method, the $L C L C$ resonant converter is tested under $25^{\circ} \mathrm{C}$ and $60{ }^{\circ} \mathrm{C}$. The experimental waveforms at $25^{\circ} \mathrm{C}$ are shown in Fig. 15 (a) and the waveforms at $60^{\circ} \mathrm{C}$ are shown in Fig. 15(b).

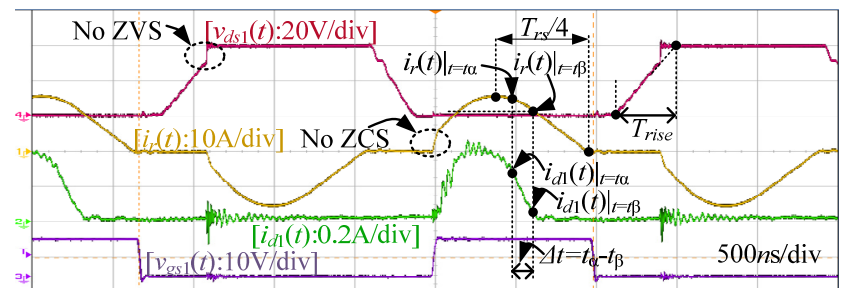

(a)

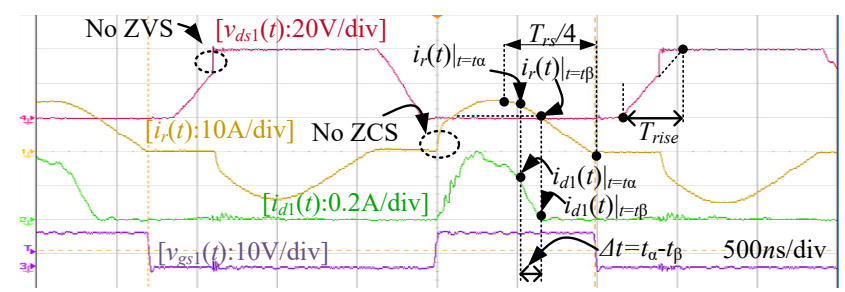

(b)

Fig. 15 Waveforms with the conventional offline measured method under different ambient temperatures: a) $25^{\circ} \mathrm{C}$; b) $60^{\circ} \mathrm{C}$.

It can be seen from Fig. 15(a) that with the offline measured results, ZCS and ZVS cannot be achieved. It is because although the temperature in the offline measurement method $\left(25^{\circ} \mathrm{C}\right)$ is the same with the operating temperature, the transformer parasitics are also affected by the operating power and the core loss [19], [20], which are not considered in the offline measurement 
method. In addition, by comparing Fig. 15(a) and Fig. 15(b), it can be seen that $v_{d s 1}(t), i_{d 1}(t)$ and $i_{r}(t)$ in two figures are slightly different, which is caused by the difference of the operating temperatures.

\section{B. Experimental results with the proposed $\mathrm{SO}^{3}$ measurement method}

The proposed $\mathrm{SO}^{3}$ measurement method is validated in this part, which follows the below procedures:

Step 1: the transformer parasitics are measured offline by an impedance analyser (E4990A) at $25{ }^{\circ} \mathrm{C}$ and the measured results are the same with the parameters shown in Table II. The offline measured parameters are used to calculate $f_{s}$ and $D$, which are $347 \mathrm{kHz}$ and $72.3 \%$, respectively.

Step 2: the offline calculated $f_{s}$ and $D$ are used to record the online experimental waveforms under two different temperatures $\left(25^{\circ} \mathrm{C}\right.$ and $\left.60{ }^{\circ} \mathrm{C}\right)$, which are shown in Fig. 15 (a) and Fig. 15(b). Since the experimental waveforms are recorded under real working conditions, the deviations of the transformer parasitics due to the working conditions have been considered.

Step 3: with the online recorded waveforms, the online transformer parasitics under different operating temperatures are calculated.

A quarter of $T_{r s}$ is measured in Fig. 15(a) and Fig. 15(b), which are $0.544 \mu \mathrm{s}$ and $0.521 \mu \mathrm{s}$. Hence, the whole period, $T_{r s}$, under different operating temperatures, is

$$
\begin{aligned}
& T_{r s(25)}=2.176 \mu \mathrm{s} \\
& T_{r s(60)}=2.084 \mu \mathrm{s}
\end{aligned}
$$

where $T_{r s(25)}$ is the resonant period between $L_{r}$ and $C_{s}$ at $25{ }^{\circ} \mathrm{C}$ while $T_{r s(60)}$ is the resonant period between $L_{r}$ and $C_{s}$ at $60^{\circ} \mathrm{C}$.

As $C_{s}$ is the detached capacitor, which is $1.0 \mu \mathrm{F}, L_{r}$ under different temperatures can be calculated by (15), which is

$$
\begin{aligned}
& L_{r(25)}=0.12 \mu \mathrm{H} \\
& L_{r(60)}=0.11 \mu \mathrm{H}
\end{aligned}
$$

where $L_{r(25)}$ is the leakage inductance at $25{ }^{\circ} \mathrm{C}$ while $L_{r(60)}$ is the leakage inductance at $60{ }^{\circ} \mathrm{C}$.

In order to calculated the online $L_{m}$, two moments, $t_{\alpha}, t_{\beta}$, are selected, which are shown in Fig. 15(a) and Fig. 15(b), respectively. The resonant current difference, the current difference of the rectifier, $D_{1}$, between $t_{\alpha}$ and $t_{\beta}$, are measured. With these measured parameters, $L_{m}$ under different temperatures is calculated by (20), which is

$$
\begin{aligned}
& L_{m(25)}=8.9 \mu \mathrm{H} \\
& L_{m(60)}=8.6 \mu \mathrm{H}
\end{aligned}
$$

where $L_{m(25)}$ is the magnetizing inductance at $25{ }^{\circ} \mathrm{C}$ while $L_{m(60)}$ is the magnetizing inductance at $60{ }^{\circ} \mathrm{C}$.

In order to calculate $C_{p}, T_{\text {rise }}$ is measured with the experimental waveforms in Fig. 15(a) and Fig. 15(b). Since $f_{r s}$ can be calculated by $T_{r s}$, with $T_{r i s e}, f_{r p}$ can be calculated by (21).

With $f_{r p}, C_{p}$ under different temperatures can be calculated with (22), which is

$$
\begin{aligned}
& C_{p(25)}=18.1 n F \\
& C_{p(60)}=18.6 n F
\end{aligned}
$$

where $C_{p(25)}$ is the parasitic capacitance at $25{ }^{\circ} \mathrm{C}$ while $C_{p(60)}$ is the parasitic capacitance at $60^{\circ} \mathrm{C}$.

With the online measured transformer parasitics in (24), (25) and (26), the online $f_{s}$ and $D$ under different temperatures are calculated, which are shown in Table III.

It can be seen that compared with the offline measured transformer parasitics shown in Table II, variations of the transformer parasitics can be found in Table III. This is caused by the operating conditions. With the online measured $f_{s}$ and $D$ under different temperatures, the waveforms are shown in Fig. 16(a) and Fig. 16(b).

TABLE III. PARASITICS OF THE TRANSFORMER BY ONLINE MEASUREMENT

\begin{tabular}{cccccc}
\hline \hline \multicolumn{6}{c}{ Online measurement result at $25^{\circ} \mathrm{C}$} \\
\hline Parameter & Value & Parameter & Value & Parameter & Value \\
\hline$L_{r(25)}$ & $0.12 \mu \mathrm{H}$ & $C_{p(25)}$ & $18.1 n \mathrm{~F}$ & $D_{(25)}$ & $68.0 \%$ \\
\hline$L_{m(25)}$ & $8.9 \mu \mathrm{H}$ & $\boldsymbol{f}_{s(25)}$ & $312 \mathrm{kHz}$ \\
\hline \multicolumn{6}{c}{ Online measurement result at $60^{\circ} \mathrm{C}$} \\
\hline Parameter & Value & Parameter & Value & Parameter & Value \\
\hline$L_{r(60)}$ & $0.11 \mu \mathrm{H}$ & $C_{p(60)}$ & $18.6 n \mathrm{~F}$ & $D_{(60)}$ & $66.4 \%$ \\
\hline$L_{m(60)}$ & $8.6 \mu \mathrm{H}$ & $\boldsymbol{f}_{s(60)}$ & $319 \mathrm{kHz}$ & & \\
\hline \hline
\end{tabular}

C. Efficiency Comparison between the traditional and the proposed $\mathrm{SO}^{3}$ measurement methods

As shown in Fig. 15 and Fig. 16, compared with the conventional measurement method, with the proposed $\mathrm{SO}^{3}$ measurement method, both ZCS and ZVS are achieved. Therefore, the switching loss are reduced. However, it is still necessary to compare the total efficiency of the converter.

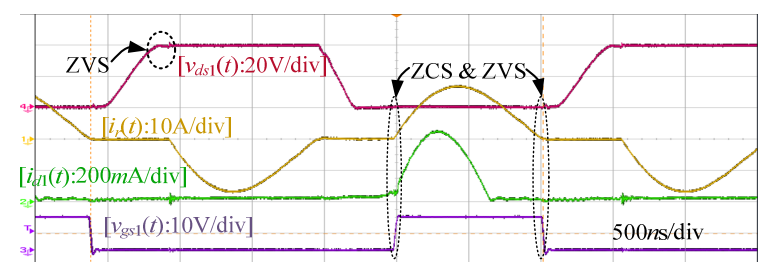

(a)

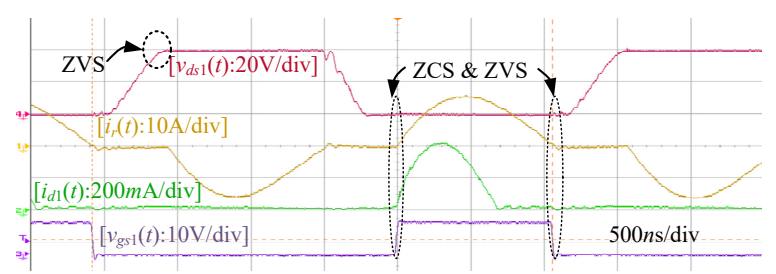

(b)

Fig. 16 Waveforms with the proposed $\mathrm{SO}^{3}$ measurement method under different operating temperatures: a) $25^{\circ} \mathrm{C}$; b) $60^{\circ} \mathrm{C}$.

The power efficiency of the $L C L C$ resonant converter with the conventional measurement method and the proposed $\mathrm{SO}^{3}$ measurement method under different input voltages and different loads are shown in Fig. 17(a) and Fig. 17(b), respectively.

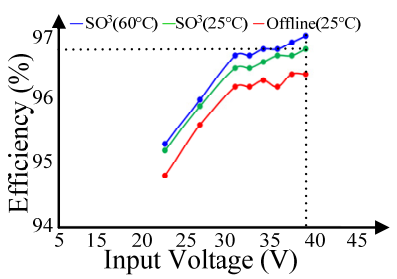

(a)

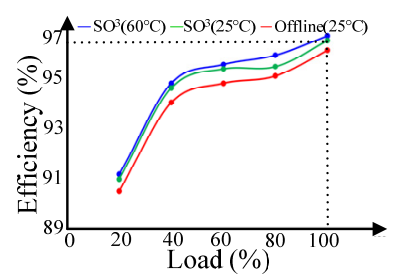

(b)
Fig. 17 Efficiency comparison: a). under different input voltages; b). under different loads.

It can be seen from Fig. 17(a), with the proposed $\mathrm{SO}^{3}$ measurement method, the efficiency under different input 
voltages are higher than that with the offline method. Similarly, with the proposed $\mathrm{SO}^{3}$ measurement method, the efficiency under different loads are higher than that with the offline method. The improvement of the efficiency can be summarized as: at first, it can be from Fig. 15 and Fig. 16 that the switching loss with the proposed $\mathrm{SO}^{3}$ measurement method is reduced, which is a crucial issue in high frequency application. Secondly, thanks to ZVS and ZCS, the oscillations are reduced and the conduction loss will be reduced accordingly. In addition, it can be seen from Fig. 17 that the efficiency under $60^{\circ} \mathrm{C}$ is generally a little higher than that under $25^{\circ} \mathrm{C}$, which is mainly because of the magnetic core. Under $60^{\circ} \mathrm{C}$, the power loss density of the magnetic core is lower than that under $25^{\circ} \mathrm{C}$, which means less core loss.

Therefore, it can be concluded that with the proposed $\mathrm{SO}^{3}$ measurement method, the efficiency of the high frequency $L C L C$ resonant converter is improved.

\section{CONCLUSIONS}

A sequential offline-online-offline $\left(\mathrm{SO}^{3}\right)$ transformer parasitics measurement method has been proposed for the high frequency $L C L C$ resonant converter in the space TWTA application, which contains three steps:

Step 1: the transformer parasitics are firstly measured by an offline impedance analyser. By these offline measured parasitic parameters, the initial switching frequency and duty cycle of the LCLC resonant converter can be calculated;

Step 2: The online waveforms of the $L C L C$ resonant converter is recorded with the initial switching frequency and duty cycle from Step 1 by oscilloscopes;

Step 3: According to the recorded waveforms in Step 2, the real transformer parasitic parameters can be calculated by mathematical equations. By these corrected transformer parasitic parameters, the final switching frequency and duty cycle of the $L C L C$ resonant converter are eventually corrected and updated to the $L C L C$ resonant converter to make it work well.

With the proposed $\mathrm{SO}^{3}$ measurement method, all the transformer parasitic parameters are measured online, which keeps the advantages of the traditional measurements while removing their limitations. The advantages of the proposed SO3 measurement method can be summarized as:

- Simplicity and low cost. In the proposed $\mathrm{SO}^{3}$ measurement method, neither extra measurement facilities nor additional online test circuit are required. Therefore, the proposed method enjoys the advantages of simplicity and low cost.

- High accuracy. In the proposed $\mathrm{SO}^{3}$ measurement method, as all the transformer parasitics are measured online, the variations of the parameters caused by the operating conditions are considered. As a result, the proposed method shares the same accuracy with the online measurement method.

The proposed method has been validated by the experiments.

\section{REFERENCES}

[1] I. Barbi and R. Gules, "Isolated DC-DC converters with high-output voltage for TWTA telecommunication satellite applications," IEEE Trans. on Power Electronics, vol. 18, no. 4, pp. 975-984, July 2003.

[2] J. M. Blanes, A. Garrigos, J. A. Carrasco, J. Ejea-Martí and E Sanchis-Kilders, "High-Efficiency Regulation Method for a Zero-Current and Zero-Voltage Current-Fed Push-Pull Converter," IEEE Trans. on Power Electronics, vol. 26, no. 2, pp. 444-452, Feb. 2011.
[3] M. Forouzesh, Y. P. Siwakoti, S. A. Gorji, F. Blaabjerg and B. Lehman, "Step-Up DC-DC Converters: A Comprehensive Review of Voltage-Boosting Techniques, Topologies, and Applications," IEEE Trans. on Power Electronics, vol. 32, no. 12, pp. 9143-9178, Dec. 2017.

[4] J. M. Blanes, A. Garrigós, R. Gutiérrez, J.A. Carrasco, E. Maset, J.B. Ejea, E. Sanchis-Kilders, A. Ferreres and J. L. Lizan "Evaluation of Gallium Nitride Transistors in Electronic Power Conditioners for TWTAs," 2015 IEEE Aerospace Conference, Big Sky, MT, 2015, pp. 1-8.

[5] B. Zhao, G. Wang and W. G. Hurley, "Analysis and Performance of $L C L C$ Resonant Converters for High-Voltage High-Frequency Applications," IEEE Journal of Emerging and Selected Topics in Power Electronics, vol. 5, no. 3, pp. 1272-1286, Sept. 2017.

[6] B. Zhao, Z. Ouyang, M. Duffy, M. A. E. Andersen and W. G. Hurley, " An Improved Partially Interleaved Transformer Structure for High-voltage High-frequency Multiple-output Applications," IEEE Trans. on Industrial Electronics, 2018. (early access) DOI: 10.1109/TIE.2018.2840499

[7] T. Senjyu, K. Kinjo, N. Urasaki, and K. Uezato, "Parameter measurement for PMSM using adaptive identification," in Proc. IEEE Int. Symp. Ind. Electron., May 2002, vol. 3, pp. 711-716.

[8] S. Morimoto, M. Sanada and Y. Takeda, "Mechanical Sensorless Drives of IPMSM With Online Parameter Identification," IEEE Trans. on Industry Applications, vol. 42, no. 5, pp. 1241-1248, 2006.

[9] Y. Kwon, J. Lee, S. Moon, B. Kwon, C. Choi and J. Seok, "Standstill Parameter Identification of Vector-Controlled Induction Motors Using the Frequency Characteristics of Rotor Bars," IEEE Trans. on Industry Applications, vol. 45, no. 5, pp. 1610-1618, Sept.-oct. 2009.

[10] T. L. Vandoorn, F. M. De Belie, T. J. Vyncke, J. A. Melkebeek and P. Lataire, "Generation of Multisinusoidal Test Signals for the Identification of Synchronous-Machine Parameters by Using a Voltage-Source Inverter," IEEE Trans. on Industrial Electronics, vol. 57, no. 1, pp. 430-439, Jan. 2010

[11] X. Zhang, Q. Zhong, V. Kadirkamanathan, J. He and J. Huang, "Source-side Series-virtual-impedance Control to Improve the Cascaded System Stability and the Dynamic Performance of Its Source Converter," in IEEE Trans. on Power Electronics. 2018. doi: 10.1109/TPEL.2018.2867272.

[12] X. Zhang and Q. Zhong, "Improved Adaptive-Series-Virtual-Impedance Control Incorporating Minimum Ripple Point Tracking for Load Converters in DC Systems," in IEEE Transactions on Power Electronics, vol. 31, no. 12, pp. 8088-8095, Dec. 2016.

[13] C. Liu, L. Qi, X. Cui and X. Wei, "Experimental Extraction of Parasitic Capacitances for High-Frequency Transformers," IEEE Trans. on Power Electronics, vol. 32, no. 6, pp. 4157-4167, June 2017.

[14] P. Xiao, G. K. Venayagamoorthy, K. A. Corzine and J. Huang, "Recurrent Neural Networks Based Impedance Measurement Technique for Power Electronic Systems," IEEE Trans. on Power Electronics, vol. 25, no. 2, pp. 382-390, Feb. 2010.

[15] Kan Liu, Qiao Zhang, Jintao Chen, Z. Q. Zhu, Jing Zhang, "Online Multiparameter Estimation of Nonsalient-Pole PM Synchronous Machines with Temperature Variation Tracking", IEEE Trans. on Industrial Electronics, vol. 58, no. 5, pp. 1776-1788, 2011

[16] M. Algreer, M. Armstrong and D. Giaouris, "Active Online System Identification of Switch Mode DC-DC Power Converter Based on Efficient Recursive DCD-IIR Adaptive Filter," IEEE Trans. on Power Electronics, vol. 27, no. 11, pp. 4425-4435, Nov. 2012.

[17] Z. Ma, X. Zhang, J. Huang and B. Zhao, "Stability Constraining Dichotomy Solution Based Model Predictive Control to Improve the Stability of Power Conversion System in the MEA," in IEEE Transactions on Industrial Electronics. doi: 10.1109/TIE.2018.2875418.

[18] J. A. A. Qahouq and Z. Xia, "Single-Perturbation-Cycle Online Battery Impedance Spectrum Measurement Method with Closed-Loop Control of Power Converter," IEEE Trans. on Industrial Electronics, vol. 64, no. 9, pp. 7019-7029, Sept. 2017.

[19] J. Huang, X. Zhang, Z. K. Shuai, X. N. Zhang, P. Wang, L. H. Koh, X. J. Fang and X. Q. Tong, "Robust Circuit Parameters Design for the CLLC-Type DC Transformer in the Hybrid AC/DC Microgrid," IEEE Trans. on Industrial Electronics, 2018. (early access)

[20] K. M. Rahman and S. Hiti, "Identification of machine parameters of a synchronous motor," IEEE Trans. on Industry Applications, vol. 41, no. 2, pp. 557-565, March-April 2005.

[21] G. Busatto, G. V. Persiano and F. Iannuzzo, "Experimental and numerical investigation on MOSFET's failure during reverse recovery of its internal diode," IEEE Trans. on Electr. Devices, vol. 46, no. 6, pp. 1268-1273, 1999.

[22] J. A. Schrock, B. N. Pushpakaran, A. V. Bilbao, W. B. Ray II, E. A. Hirsch, M. D. Kelley, S. L. Holt and S. B. Bayne, "Failure Analysis of 1200-V/150-A SiC MOSFET Under Repetitive Pulsed Overcurrent Conditions," IEEE Trans. on Power Electronics, vol. 31, no. 3, pp. 1816-1821, March 2016.

[23] N. Shafiei, M. Pahlevaninezhad, H. Farzanehfard and S. R. Motahari, "Analysis and Implementation of a Fixed-Frequency LCLC Resonant Converter with Capacitive Output Filter," IEEE Trans. on Industrial Electronics, vol. 58, no. 10, pp. 4773-4782, Oct. 2011.

[24] C. M. Bingham, Y. A. Ang, M. P. Foster and D. A. Stone, "Analysis and Control of Dual-Output $L C L C$ Resonant Converters With Significant 
Leakage Inductance," IEEE Trans. on Power Electronics, vol. 23, no. 4, pp. 1724-1732, July 2008 .

[25] R. L. Lin and L. H. Huang, "Efficiency Improvement on LLC Resonant Converter Using Integrated $L C L C$ Resonant Transformer," IEEE Trans. on Industry Applications, vol. 54, no. 2, pp. 1756-1764, March-April 2018.

[26] Y. Kulvitit, P. Opanuruk and T. Tansatit, "Effects of Internal Feedback and Gate-Drive Signal on the Turn-Off Loss of MOSFET ZVS," IEEE Trans. on Industry Applications, vol. 45, no. 6, pp. 2064-2072, Nov.-dec. 2009.

[27] W. Chen, P. Rong and Z. Lu, "Snubberless Bidirectional DC-DC Converter with New CLLC Resonant Tank Featuring Minimized Switching Loss," IEEE Trans. on Industrial Electronics, vol. 57, no. 9, pp. 3075-3086, 2011.

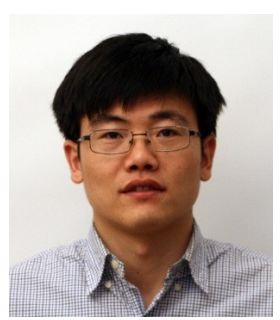

Bin Zhao (M'18) received the B. S. degree in electrical engineering from Nanjing Agricultural University, Nanjing, China, in 2012 and the Ph.D. degree from Institute of Electronics, Chinese Academy of Sciences, Beijing, China, in 2017.

From September 2015 to December 2016, he was a Visiting Scholar with the National University of Ireland, Galway, Ireland. From January 2017 to January 2018, he was a postdoc researcher with the Department of Electrical Engineering, Technical University of Denmark. From February 2018 to January 2019, he was a research fellow with Energy Research Institute @ NTU, Nanyang Technological University. Since January 2019, he has been with Space Travelling-wave Tube Research \& Development Center, Institute of Electronics, Chinese Academy of Sciences, as a professor. His current research interests include high frequency magnetic simulation, design and integration in power electronics and resonant converters.

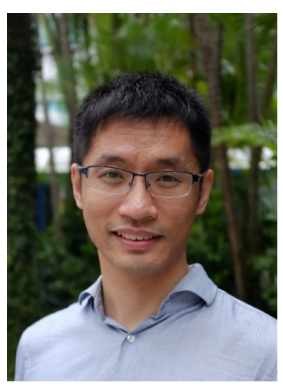

Xin Zhang (M'15) received the Ph.D. degree in Automatic Control and Systems Engineering from the University of Sheffield, U.K., in 2016 and the Ph.D. degree in Electronic and Electrical Engineering from Nanjing University of Aeronautics \& Astronautics, China, in 2014. Currently, he is an Assistant Professor at the School of Electrical and Electronic Engineering of Nanyang Technological University. He services as the AE of IEEE TIE/JESTPE and IET Power electronics. He is also the TPC member in IEEE IA/PELS Singapore joint Chapter. Dr Xin Zhang has received the highly-prestigious Chinese National Award for Outstanding Students Abroad in 2016. He is generally interested in power electronics, power system, and advanced control theory, together with their applications in various sectors.

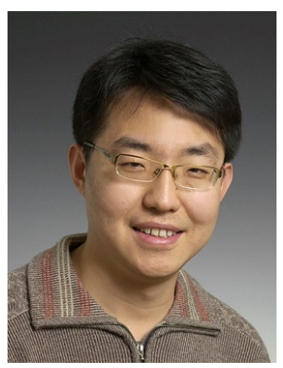

Zhe Zhang (M'11-SM'16) received the B.Sc. and M.Sc. degrees in power electronics from Yanshan University, Qinhuangdao, China, in 2002 and 2005, respectively, and the $\mathrm{PhD}$ degree from the Technical University of Denmark, Kgs. Lyngby, Denmark, in 2010.

$\mathrm{He}$ is currently an Associate Professor in the Department of Electrical Engineering, at the Technical University of Denmark (DTU). Since Jan. 2018, he has been Head of Studies in charge of Electrical Engineering MSc Programme, which is one of the largest MSc programme at DTU. From 2005 to 2007, he was an Assistant Professor at Yanshan University. From June 2010 to August 2010, he was with the University of California, Irvine, CA, USA, as a visiting scholar. He was an Assistant Professor at the Technical University of Denmark during 2011 and 2014. He has authored or co-authored more than 130 transactions and international conference papers and filed 8 patent applications. He has supervised over $10 \mathrm{PhD}$ students since 2013. Dr. Zhang's current research interests include applications of wide bandgap devices, high frequency dc-dc converters, multiple-input dc-dc converters, soft-switching power converters and multi-level dc-ac inverters for renewable energy systems (RES), hybrid electric vehicles (HEV) and uninterruptable power supplies (UPS); piezoelectric-actuator and piezoelectric-transformer based power conversion systems.

Dr. Zhang has received several awards and honors including Best Paper Award in IEEE ECCE, Best Paper Award in IEEE IGBSG, Best Teacher of the Semester, Chinese Government Award for Outstanding
Students Abroad, etc. He is also a guest associate editor in IEEE Transactions on Industrial Electronics. 